\title{
Antibacterial and antifungal activities of Lespedeza cuneata extract against Candida albicans.
}

\author{
Hee-Jin Hong, Na-Ra Son, Wang-Yong Yang, Jeong-Min Lee, Ji-Ho Kim, Se-Mi Jang, Seoul-Hee Nam* \\ Department of Dental Hygiene, College of Health Sciences, Kangwon National University, Samcheok-Si, Republic of \\ Korea
}

\begin{abstract}
As side effects of chemical antifungal agents has been reported, this study was conducted to confirm the reported antifungal effect of Lespedeza cuneata on Candida albicans ( $C$. albicans), and to investigate the usability of Lespedeza cuneata for the prevention and treatment of oral diseases. Lespedeza cuneata was placed in $80 \%$ ethanol at a 5:1 ratio, and was immersed therein for $24 \mathrm{~h}$ at a $65^{\circ} \mathrm{C}$ dry oven. It was concentrated using a rotary vacuum evaporator after filtration. The concentrated Lespedeza cuneata extract was used after being dried using a $-80^{\circ} \mathrm{C}$ freeze dryer. The antifungal effect of Lespedeza cuneata extract on $C$. albicans was investigated using the paper disc method, which presents the bacterial inhibitory area by $1.5,2.5,5,10$, and $20 \mathrm{mg} / \mathrm{ml}$ concentrations, as well as the colony-forming units (CFUs) method, which confirms the colony formation on the yeast mold (YM) agar medium. The measurement of the clear paper disc circle using a growth inhibitory section showed bacterial inhibition, with $13 \mathrm{~mm}$ at $20 \mathrm{mg} / \mathrm{ml}, 11 \mathrm{~mm}$ at $10 \mathrm{mg} / \mathrm{ml}$, and $10 \mathrm{~mm}$ at $5 \mathrm{mg} / \mathrm{ml}$. As the concentration of Lespedeza cuneata extract increased, greater bacterial growth inhibition was observed. The survival rate of $C$. albicans calculated from the CFUs showed more distinct bacterial growth inhibition as the concentration increased. Based on these results, alleviation of the problems and side effects of the use of the existing antibiotics against oral candidiasis was confirmed, as well as the usability of Lespedeza cuneata for the treatment and prevention of oral diseases.
\end{abstract}

Keywords: Antimicrobial, Antifungal, Lespedeze cuneata, Candida albicans.

Accepted on November 21, 2018

\section{Introduction}

Oral diseases have been presented as continuous health problems worldwide [1]. Dental caries and periodontitis are two of the serious oral diseases threatening the oral health of modern people [2]. Therefore, the interest in oral hygiene management has been rising to prevent diseases related to the presence of bacteria in the oral cavity, such as inflammation in the oral region [3].

There is an association between oral diseases and the microorganisms in the oral cavity [4]. Dental caries occurs due to bacteria like Streptococcus mutans or Streptococcus sobrinus, and periodontitis is associated with gram-negative bacilli like Porphyromonas gingivalis, Actinobacillus actinomycetemcomitans, and Fusobacterium nucleatum. These bacteria are frequently found in periodontal lesions, and studies on their association with the onset and progression of periodontal diseases have been reported [5]. When dental hygiene becomes poor, the bacterial growth increases locally, and the balance between the host's resistance and the microorganisms' pathogenicity is threatened, leading to a disease. The infection caused by the normal flora in the oral cavity is called "intrinsic infection," and actinomycosis or candidiasis is the most representative intrinsic infection [6].

Oral candidiasis is a fungal opportunistic infection caused mostly by Candida albicans (C. albicans) among the candida types, and exists without any clinical symptom of mucosal disease in about $60 \%$ of healthy adults [7]. Although $C$. albicans exists in the oral cavity in a non-pathogenic state, it can cause infection due to the many factors that cause immunosuppression of the host, and can cause opportunistic infection when it attaches to the oral epithelial cells or dentures [8]. Antifungal agents for decreasing C. albicans have been developed, and the representative antifungal agents used for treatment are amphotericin B, miconazole, nystatin, and chlorhexidine [9]. Nystatin is the most commonly used for candidiasis, but it is difficult to use due to its bitter taste and nasty flavor [10]. In addition, chlorhexidine (CHX) has a bitter taste and causes a burning sensation in the mucosa; in addition, it has been reported that its effect significantly decreases when organisms exist [11]. CHX has limited usability in patients due to the continuing reports on how it adversely affects the patient's sense of taste or causes teeth discoloration [12]. Furthermore, although some antibiotics used for treatment are safe when used with the common doses, some have life- 
threatening side effects [13]. "Antibiosis," which may exist among microorganisms, means the prevention of growth or the life of another microorganism [14]. Antibiotic use in early childhood is associated with various health problems, including worsening allergic disease, obesity, and inflammatory bowel disease [15].

Considering the foregoing, the interest in traditional plants or natural substances has increased of late for use in the prevention and treatment of oral diseases without any harmful effect on the human body [16]. Lespedeza cuneata is a perennial plant belonging to the legume family that has various names, including bisuri and samyupcho, and is distributed in South Korea, Japan, China, Taiwan, etc. It is a very common plant used for creating a surface cover and for soil fertility improvement in a desolated land, and has been used as an herbal medicine that effectively treats sexual impotence, premature ejaculation, ganacratia, cough, and asthma [17]. Lespedeza cuneata has a bitter and spicy taste and a warm character, does not have toxicity, and can be administered using various methods [18]. Furthermore, it has been reported to have an antioxidant effect, and it is known that the appropriate intake of antioxidants can reduce the risk caused by oxidation [19].

Although many studies have been conducted to investigate the antibacterial effect of natural-substance extracts on oralcandidiasis-causing bacteria to replace antibiotics for oral candidiasis treatment [20-22], no studies have been conducted to investigate the antibacterial effect of Lespedeza cuneata extract on oral candidiasis. Therefore, this study was conducted to investigate the effect of Lespedeza cuneata extract on $C$. albicans, and to confirm the possibility of using Lespedeza cuneata extract for the treatment and prevention of oral candidiasis.

\section{Materials and Methods}

\section{C. albicans culture}

C. albicans (KCTC 7965/ATCC 10231) were grown in a yeast mold broth (YM, Difco, USA) for $24 \mathrm{~h}$, and were incubated at $37^{\circ} \mathrm{C}$.

\section{Lespedeza cuneata extraction}

Dried Lespedeza cuneata produced in Sancheong country in South Gyeongsang Province was purchased from Jirisan Cheongjeong Yakcho Ltd. It was then put into $80 \%$ ethanol about 5 times its amount and was stored for $24 \mathrm{~h}$ at $60^{\circ} \mathrm{C}$. The supernatant was then collected and was filtered using filter paper (filter paper grade no. 2); it was concentrated after separating the ethanol using a rotary vacuum evaporator (N-1300E.V.S EYELA Co., Japan). The Lespedeza cuneata was dried using a freeze dryer (FD5508, Ilshin Lab, Yangjukun, Kyunggi-do, South Korea) and was applied after being dissolved in dimethyl sulfoxide (DMSO, Sigma-Aldrich, St. Louis, Missouri, USA).

\section{Disc diffusion method}

A paper disc was placed on top of YM agar medium, and 100 $\mu 1$ Lespedeza cuneata extract was applied at 1.25, 2.5, 5, 10, and $20 \mathrm{mg} / \mathrm{ml}$ concentrations, respectively. After culturing for $24 \mathrm{~h}$, a formed growth inhibitory area was identified.

\section{Measurement of the colony-forming units (CFUs)}

$1 \mathrm{ml}$ Lespedeza cuneata extract was applied to YM agar at $1.25,2.5,5,10$, and $20 \mathrm{mg} / \mathrm{ml}$ concentrations, respectively, and was absorbed then cultured for $24 \mathrm{~h}$ at $37^{\circ} \mathrm{C}$ to collect the colonies formed.

\section{Statistical analysis}

The statistical analysis was performed with IBM SPSS ver. 21.0 (IBM Co., Armonk, NY, USA). The antibacterial effect were analysed through one-way ANOVA and Tukey's post hoc test at a 0.05 significance level.

\section{Results}

\section{Measurement of the clear zone}

Based on the antibacterial activity investigation against $C$. albicans, a bacterial growth inhibitory pattern was observed around the paper disc. The inhibitory areas were shown as 13 $\mathrm{mm}$ at $20 \mathrm{mg} / \mathrm{ml}, 11 \mathrm{~mm}$ at $10 \mathrm{mg} / \mathrm{ml}$, and $10 \mathrm{~mm}$ at $5 \mathrm{mg} / \mathrm{ml}$, and it was confirmed that the bacterial growth inhibitory effect increased as the Lespedeza cuneata extract increased (Figure 1).

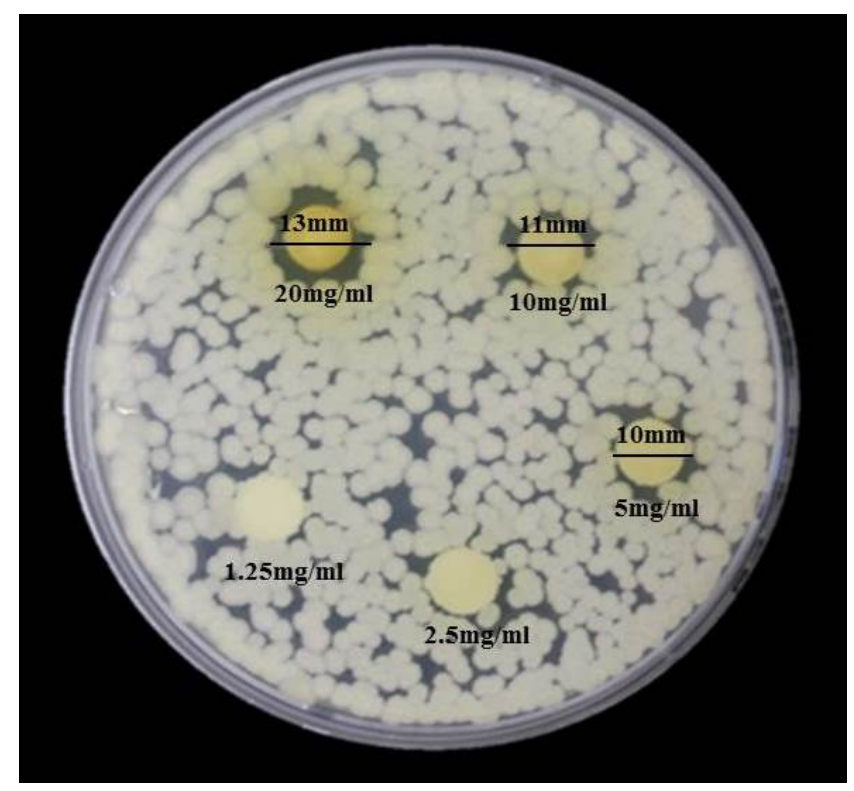

Figure 1. C. albicans growth inhibitory area by Lespedeza cuneata extracts concentration using the disc diffusion method.

\section{Number of CFUs for antibacterial-effect evaluation}

It was confirmed that the antibacterial effect of Lespedeza cuneata extract became stronger as its concentration increased from $1.5 \mathrm{mg} / \mathrm{ml}$ to $2.5,5,10$, and $20 \mathrm{mg} / \mathrm{ml}$ (Figure 2). 
Furthermore, the survival rates of the $C$. albicans calculated from the CFUs, as shown in Figure 3, were $2.16 \times 10^{7}(C$. albicans) in the control, $2.40 \times 101$ at $20 \mathrm{mg} / \mathrm{ml}, 7.50 \times 10^{3}$ at $10 \mathrm{mg} / \mathrm{ml}, 1.44 \times 10^{4}$ at $5 \mathrm{mg} / \mathrm{ml}, 2.33 \times 10^{4}$ at $2.5 \mathrm{mg} / \mathrm{ml}$, and $3.99 \times 10^{4}$ at $1.25 \mathrm{mg} / \mathrm{ml}$, which showed an antibacterial effect at a low concentration of $1.25 \mathrm{mg} / \mathrm{ml}$ and a stronger antibacterial effect from the growth inhibition as the concentration increased (Figure 3). There was a distinct difference between the control group and the Lespedeza cuneata extract group $(\mathrm{p}<0.05)$.

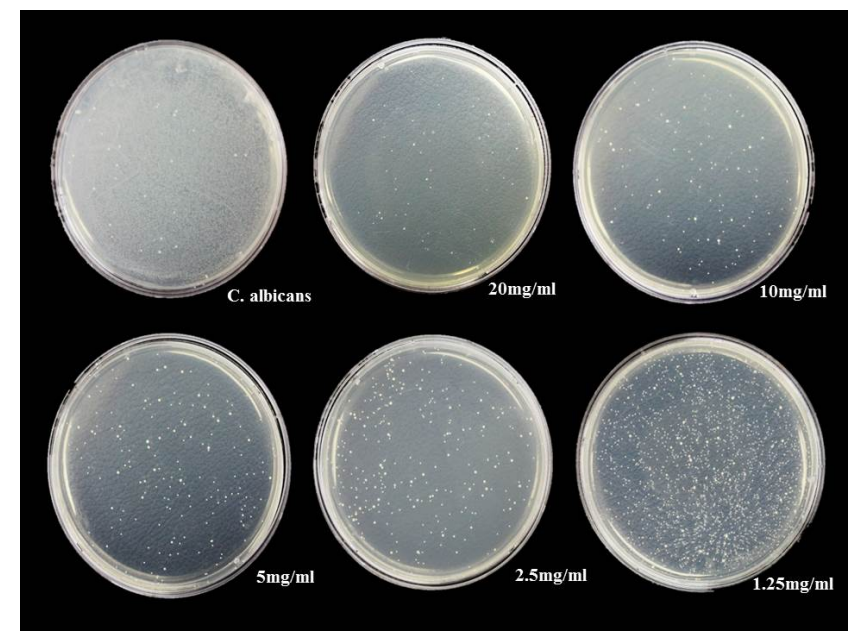

Figure 2. Antibacterial effect of Lespedeza cuneata extract against $C$. albicans.

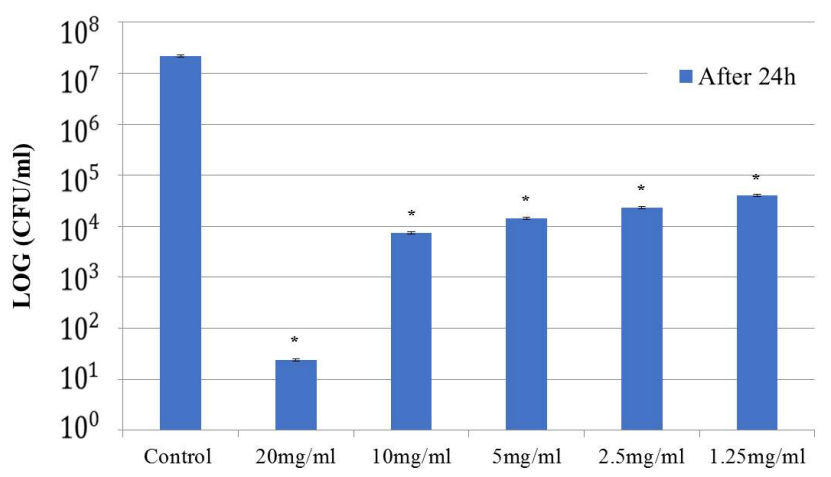

Figure 3. Bacterial survival rate of the counted CFUs against each Lespedeza cuneata extract concentration. ${ }^{*}$ The p-values are determined by ANOVA $(p<0.05)$.

\section{Discussion}

C. albicans are normal flora in the oral cavity and generally do not cause problems in healthy adults [23]. It has been reported that the incidence rate of oral candidiasis from $C$. albicans separated from the oral cavity is about $35-40 \%$ in healthy adults [24].

Oral candidiasis treatment should be conducted based on four principles: fast and accurate infection diagnosis, causal factor or underlying disease prediction, candida infection type evaluation, and use of appropriate antifungal agents [25].
Although antibiotics are generally used to prevent and treat oral diseases, several side effects have been reported. Excessive use of chemical agents can result in unwanted side effects, such as infection from other bacteria, vomiting, or diarrhea [26]. It has been reported that other antimicrobialcontaining chemical agents can show toxicity or cause teeth discoloration and an association between oral cancer and ethanol, which is commonly found in typical mouthwashes, has been reported [27]. When a potent chemical agent is added, however, the pathogens and normal flora in the oral cavity may be eliminated. Therefore, the use of natural extracts has been recommended to inhibit the growth of pathogenic bacteria while maintaining the normal flora in the oral cavity [28].

For the foregoing reasons, studies on natural antifungal substances that can be used to prevent disease or inhibit disease progression have been reported of late [29]. Seong et al. [20] reported that gallnut extract using methanol showed antifungal activity against $C$. albicans. Shin et al. [21] investigated the antifungal activity of raspberry extract at various concentrations $(2,4,8,15,30,60$, and $120 \mathrm{mg} / \mathrm{ml})$ against $C$. albicans and reported that bacterial growth inhibition was shown from the $8 \mathrm{mg} / \mathrm{ml}$ concentration of the extract. Choi et al. [22] applied Acanthopanax sessiliflorum extract against $C$. albicans, and the results showed an antibacterial effect at 20 $\mathrm{mg} / \mathrm{ml}$ while no bacteria were observed at $50 \mathrm{mg} / \mathrm{ml}$.

This study investigated the possibility of the substitution of the existing antibiotics by Lespedeza cuneata natural extract to address the problem of side effects from the use of the existing antibiotics. The results showed an antibacterial effect from the lowest concentration of $1.25 \mathrm{mg} / \mathrm{m}$, and the antibacterial effect became stronger as the concentration increased. It was found that the extract had an antibacterial effect based on the $10^{-6}$ bacterial inhibition at $20 \mathrm{mg} / \mathrm{ml}$. Based on the results of the study, the natural antibiotic Lespedeza cuneata extract showed high antibacterial activity and growth inhibition against $C$. albicans, the bacteria that cause oral candidiasis.

Therefore, it is suggested that applying Lespedeza cuneata extract to the oral cavity with oral candidiasis can alleviate the problems and side effects of the use of the existing antibiotics, and can be used for the treatment and prevention of oral candidiasis. It is expected that Lespedeza cuneata extract will be used as a natural antibiotic substance and will become the next-generation preferred antibacterial agent.

\section{Conclusion}

This study confirmed the antibacterial effect of Lespedeza cuneata extract against $C$. albicans, which causes fungal infection in the oral cavity, by inhibiting its growth. Lespedeza cuneata extract inhibited the growth of $C$. albicans, and its growth inhibitory effect became stronger as its concentration increased. Based on these results, Lespedeza cuneata extract can be added to oral hygiene products such as toothpastes or mouthwashes as a substitute for the antibiotics currently being used for the treatment and prevention of oral candidiasis. 


\section{Acknowledgement}

This research was supported by Basic Science Research Program through a National Research Foundation of Korea (NRF) grant funded by the Ministry of Science, ICT, and Future Planning (2017R1C1B5074410).

\section{References}

1. Petersen PE, Bourgeois D, Ogawa H, Estupinan-Day S, Ndiaye C. The global burden of oral diseases and risks to oral health. Bull World Health Organ 2005; 83: 661-669.

2. Cha JD, Jeong MR, Jeong SI, Lee KY. Antibacterial activity of sophoraflavanone $\mathrm{G}$ isolated from the roots of Sophora flavescens. J Microbiol Biotechnol 2007; 17: 858-864.

3. Choi MH. A survey research on industrial workers oral examination status and oral health education request level. J Korean Acad Dent Hyg Edu 2010; 10: 185-195.

4. Howard F, Jenkinson, Richard J, Lamont. Oral microbial communities in sickness and in health. Trends Microbiol 2005; 13: 589-595.

5. Takarada K, Kimizuka R, Takahashi N, Honma K, Okuda $\mathrm{K}$, Kato T. A comparison of the antibacterial efficacies of essential oils against oral pathogens. Oral Microbiol Immunol 2004; 19: 61-64.

6. Loesche W. Dental caries and periodontitis: contrasting two infections that have medical implications. Infect Dis Clin North Am 2007; 21: 471-502.

7. Darwazeh AM, Hammad MM, Al-Jamaei AA. The relationship between oral hygiene and oral colonization with Candida species in healthy adult subjects. Int J Dent Hyg 2010; 8: 128-133.

8. Lowell AG, Stephen IK, Barbara AG, Amy SP, David JL, Klaus W. Fitzpatricks dermatology in general medicine. New York McGraw-Hill 2012; 2298-2307.

9. Lee HO, Jeon JY, Kim KJ, Han DM, Han KY. Susceptibility test of Candida albicans isolated from Oral cavity. J Korean Acad Dent Health 1997; 21: 553-561.

10. Martin MV, Farrelly PJ, Hardy P. An investigation of the efficacy of nystatin for the treatment of chronic atrophic candidosis (denture sore mouth). Br Dent J 1986; 160: 201-204.

11. Filoche SK, Soma K, Sissons CH. Antimicrobial effects of essential oils in combination with chlorhexidine digluconate. Oral Microbiol Immunol 2005; 20: 221-225.

12. Kenrad B. Toxin effects from chlorhexidine gluconate: case report. Tandlaegebladet 1990; 94: 489-491.

13. Lazarou J, Pomeranz BH, Corey PN. Incidence of adverse drug reactions in hospitalized patients: a meta-analysis of prospective studies. JAMA 1998; 279: 1200-1205.

14. Hoel D, Williams DN. Antibiotics: past, present, and future. Unearthing natures magic bullets. Postgrad Med 1997; 101: 114-118, 121-122.

15. Lazarou J, Pomeranz BH, Corey PN. Incidence of adverse drug reactions in hospitalized patients: a meta-analysis of prospective studies. JAMA 1998; 279: 1200-1205.
16. Lis-Balchin M. Essential oils and aromatherapy: their modern role in healing. J R Soc Health 1997; 117: 324-329.

17. Kim SJ, Kim DW. Antoxidative activity of hot water and ethanol extracts of Lespedeza cuneata seeds. Korean J Food Preserv 2007; 14: 332-335.

18. Ahn DK. Illustrated book of Korean medicinal herbs. Seoul, Kyohuk Publishing 1988; 946-947.

19. Valko M, Leibfritz D, Moncol J, Cronin MT, Mazur M, Telser J. Free radicals and antioxidants in normal physiological functions and human disease. Int $\mathrm{J}$ Biochem Cell Biol 2007; 39: 44-84.

20. Seong IW. Antifungal activity of the extracts from Galla rhois against Candida albicans. Kor J Med Mycol 2007; 12: $175-179$.

21. Shin AR, Ohk SH, Choi CH, Hong SJ. Growth inhibition effect of Rubus coreanus Miquel on Candida albicans. J Korean Acad Oral Health 2015; 39: 168-173.

22. Choi YS, Kim NH, Kim HJ, An SJ, Lee BN, Jung MJ, Hwang JY, Nam SH. A study on the antibacterial effect of Acanthopanax sessiliflorum on inflammatory diseases in the oral cavity. Biomed Res 2017; 28: 8376-8380.

23. Akpan A, Morgan R. Oral candidiasis. Postgrad Med J 2002; 78: 455-459.

24. Lucas VS. Association of psychotropic drugs, prevalence of denture-related stomatitis and oral candidosis. Community Dent Oral Epidemiol 1993; 21: 313-316.

25. Goins RA, Ascher D, Waecker N, Arnold J, Moorefield E. Comparison of fluconazole and nystatin oral suspensions for treatment of oral candidiasis in infants. Pediatr Infect Dis J 2002; 21: 1165-1167.

26. Chung JY, Choo JH, Lee MH, Hwang JK. Anticariogenic activity of macelignan isolated from Myristica fragrans(nutmeg) against Streptococcusmutans. Phytomedicine 2006; 13: 161-166.

27. Elisabeth KK, Juliane S. Amine fluoridegel affects the viability and the generation of superoxide anions in human polymorphonuclear leukocytes: an in vitro study. Eur J Oral Sci 2002; 110: 296-301.

28. Lis-Balchin M. Essential oils and aromatherapy: their modern role in healing. J R Soc Health 1997; 117: 324-329.

29. Takarada K, Kimizuka R, Takahashi N, Honma K, Okuda $\mathrm{K}$, Kato T. A comparison of the antibacterial efficacies of essential oils against oral pathogens. Oral Microbiol Immunol 2004; 19: 61-64.

\section{*Correspondence to}

Seoul-Hee Nam

Department of Dental Hygiene

College of Health Sciences

Kangwon National University

Republic of Korea 